\title{
Study of Critically Ill Children Presenting with Cardiopulmonary Failure to Emergency Sevices Room.
}

\author{
Dr.M.Sanjeevappa ${ }^{1}$, Dr.T.Madhu Sudhan ${ }^{2}$ \\ ${ }^{1}$ (Assistant Professor, Department Of Pediatrics, Government Medical College, Ananthapuramu, Andhra \\ Pradesh, India) \\ ${ }^{2}$ (Assistant Professor, Department Of Anesthesiology, Government Medical College, \\ Ananthapuramu, Andhra Pradesh, India).
}

\begin{abstract}
:
Introduction: Cardiac arrest predominantly observed in children younger than 1 year. About 60,000 children per year suffer from Cardiac arrest in united states. The aim of the present study is to know the magnitude and epidemiology of cardiopulmonary arrest \& cardiopulmonary failure and outcome in existing pediatric intensive care units.

Materials and Methods: All children were assessed according to PALS guidelines [8] for cardio pulmonary failure and cardio pulmonary arrest, which consist of general assessment, primary assessment, secondary assessment and tertiary assessment.

Results: Children culminating into CPR an either progressing from respiratory failure (52.1\%) (or) progressively worsening from shock (47.8\%), and no direct cardiac event recorded. Mortality rate was observed in 18 (43.4\%) CPF patients out of 23, even after Cardiopulmonary Resuscitation. Among 87 CPF and CPA patients, survival rate was observed in 18 patients (20.6\%). Survival rate is nil in CPA patients. Majority of deaths were observed in $<3$ years of age group.

Conclusion: Studies are needed in India to know the effectiveness of PALS courses in reviving the case of $C P A / C P F$ and also to find out the lacunae in implementing PALS courses, so that they can be rectified and more number of children is given new life.
\end{abstract}

Keywords: Cardiac arrest, Cardiopulmonary Failure, Mortality rate.

\section{Introduction}

Cardiac arrest (CA) also called cardiopulmonary arrest is the cessation of circulation of blood as a result of absent or ineffective cardiac mechanical activity [1]. Cessation of circulation and resulting organ and tissue ischemia can cause cell, organ and patient death if not rapidly reverse [2,3].

Cardiac arrest predominantly observed in children younger than 1 year. About 60,000 children per year suffer from CA in united states [4]. Hypoxic Arrest is the most common pathophysiologic mechanism of cardiac arrest in infants and children through adolescence. It is the terminal event of progressive tissue hypoxia and acidosis caused by respiratory failure, shock and cardiopulmonary failure. Regardless of initiating event or disease process the final common path way preceding asphyxial arrest is the development of cardio pulmonary failure.

Cardiac arrest causes are respiratory failure due to airway obstruction, acute pulmonary edema, shock, arrhythmia. Cardiac arrest is recognized by absence of signs of cardio respiratory function (no movement, no breathing or response to rescue breaths, no carotid pulse) and arrest rhythm on the cardiac monitor (monitoring is not mandatory for recognition of cardiac arrest).

During the literature search Indian scenario doesn't reveal much studies conducted regarding outcome of cardiopulmonary arrest and cardio pulmonary failure in pediatric intensive care unit in the setting of Govt. Hospitals. The outcome of out of hospital cardiopulmonary arrest is between $7.5-11.2$ patients per 100,000 persons-years [5-7]. in the western world and the outcome of cardiopulmonary failure is between $70-90 \%$, but studies do not exist in present setup.

Hence the study was under taken to know the magnitude of cardiopulmonary arrest and cardiopulmonary failure, the epidemiology of cardiopulmonary arrest and cardiopulmonary failure and outcome in existing pediatric intensive care units.

The result of the study in relation to studies in the western world can reflect the magnitude of the need to improve our pediatric intensive care units. 


\section{Materials And Methods}

All the cases of cardio pulmonary failure and cardio pulmonary arrest satisfying the "Pediatric Advanced Life Support" (PALS) guidelines[8] for hypotension respiratory failure and cardio pulmonary arrest admitted into department of pediatrics Govt. Medical College and Hospital, Ananthapuramu over a period of one year (2014) were included in this study. Ethical committee has approved and informed consent has taken from all the patients.

\subsection{Inclusion Criteria:}

Age group of 2 months to 18 years and Child presented with cardio pulmonary failure or cardio pulmonary arrest to the emergency service room as per the pediatric advanced life support guidelines.

\subsection{Exclusion Criteria:}

Children with isolated respiratory failure at the time of admission with stable circulated status.

All the children on admission were assessed by a through history and clinical examination. All children were assessed according to PALS guidelines [8] for cardio pulmonary failure and cardio pulmonary arrest, which consist of general assessment, primary assessment, secondary assessment and tertiary assessment. Children were managed according to PALS guidelines [8], during the assessment if any life threatening abnormality is present, it has corrected before going to next step in the assessment. After stabilizing the child supportive therapy and specific therapy initiated according to etiological diagnosis.

\subsection{Statistical Analysis:}

Analysis was carried out at the end of study period with the use of Graph pad software under Fischer's exact test. The $\mathrm{p}$ value below 0.05 is considered as significant.

\section{Results}

The total of 5432 cases admitted during period of one year study. Total number of cases including cardiopulmonary failure (CPF) and cardiopulmonary arrest (CPA) are $87(1.60 \%)$, out of which $64(1.17 \%)$ were with cardiopulmonary arrest and $23(0.42 \%)$ children were with cardiopulmonary failure. There is a slight female preponderance among both $\mathrm{CPF}$ and $\mathrm{CPA}$.

$65.1 \%$ of cases observed in $<3$ years age, rest of cases in above 3 years of age. Maximum number of cases seen in $<1$ year constituting $43.4 \%$ with slight female preponderance (56.52\% Vs $43.4 \%$ ) (Table No.1).

Table No. 1: Showing age and sex wise distribution of cardiopulmonary failure cases.

\begin{tabular}{|l|l|l|l|l|l|l|}
\hline & $<1$ year & $1-3$ years & $4-5$ years & $6-12$ years & Total & Percentage \\
\hline Male & 4 & 1 & 1 & 4 & 10 & $43.4 \%$ \\
\hline Female & 7 & 3 & 0 & 3 & 13 & $56.52 \%$ \\
\hline Total & 10 & 5 & 1 & 6 & 23 & $100 \%$ \\
\hline Percentage & $43.4 \%$ & $21.7 \%$ & $4.3 \%$ & $26.08 \%$ & $100 \%$ & \\
\hline
\end{tabular}

Majority of cases (95.6\%) with paleness rather than cyanosis (4.3\%). All the children presented with hypotension but recordable BP in hypotension range seen in $39.1 \%$ of cases. Children culminating into CPR an either progressing from respiratory failure $(52.1 \%$ ) (or) progressively worsening from shock $(47.8 \%)$, and no direct cardiac event recorded (Table No.2).

Table No.2 Percentage of different parameters assessed among CPF cases.

\begin{tabular}{|l|l|l|}
\hline Clinical features & No. of CPF cases (n=23) & Percentage \\
\hline Color of the baby by General Assessment & 22 & $95.6 \%$ \\
\hline Cyanosed & 1 & $4.3 \%$ \\
\hline Pale & \multicolumn{2}{|l|}{} \\
\hline Blood pressure & 14 & $60.8 \%$ \\
\hline BP not recordable & 9 & $39.1 \%$ \\
\hline BP recordable & \multicolumn{2}{|l|}{} \\
\hline Respiratory rate & 4 & $17.3 \%$ \\
\hline Tachypnoea & 19 & $82.6 \%$ \\
\hline Bradypnoea & \multicolumn{2}{|l|}{} \\
\hline Fever & 20 & $86.9 \%$ \\
\hline With fever & 3 & $13 \%$ \\
\hline Without fever & 12 & $52.1 \%$ \\
\hline Initial event of CPF & 11 & $47.8 \%$ \\
\hline Primary Respiratory failure & 11 & - \\
\hline Primary Shock & 0 & \\
\hline Primary Cardiac & \multicolumn{2}{|l|}{} \\
\hline
\end{tabular}


Mortality rate was observed in $18(43.4 \%)$ CPF patients out of 23 , even after Cardiopulmonary Resuscitation. Among $87 \mathrm{CPF}$ and CPA patients, survival rate was observed in 18 patients (20.6\%). Survival rate is nil in CPA patients. Majority of deaths were observed in $<3$ years of age group (12 out of 20 CPF deaths) (Fig No.1). Age of the child does not have statistically significant (p-1.000) impact on outcome of cardiopulmonary failure.

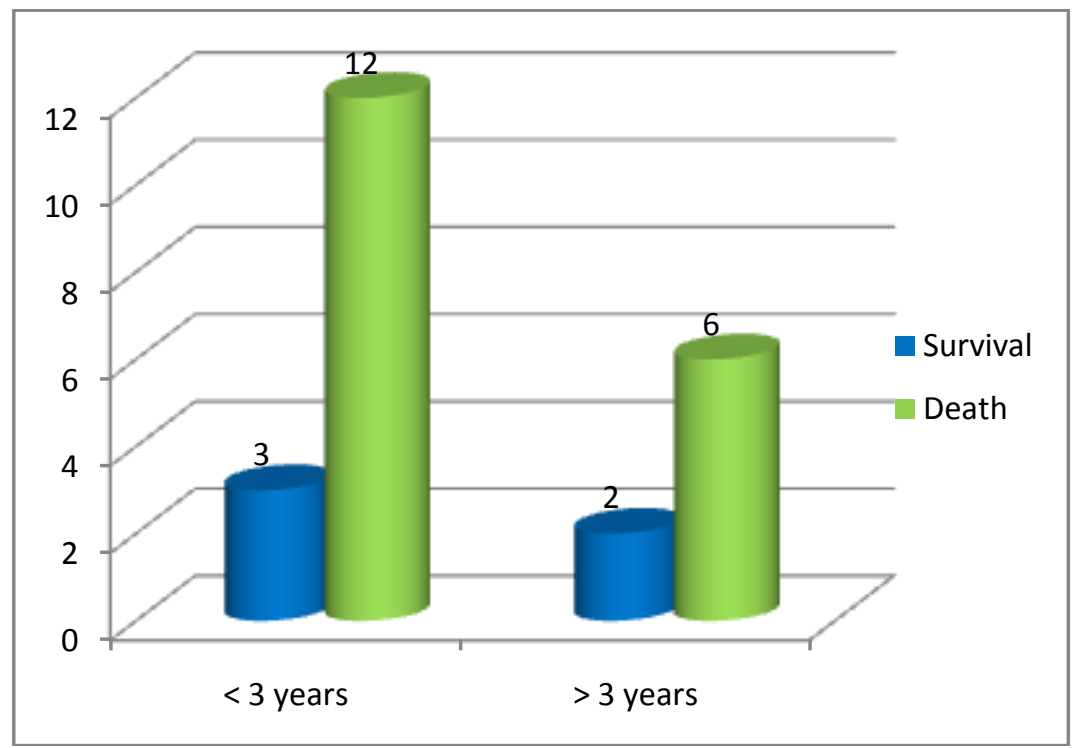

Fig No.1 Showing CPF deaths in relation to age.

Deaths among CPF cases after resuscitation were observed in relation to various clinical features (Table No.3). BP recordability, respiratory rate and respiratory failure/shock in children with cardiopulmonary failure with hypotension does not have statistically significant impact on the outcome of cardiopulmonary failure.

Table No.3 Showing deaths of CPF patients after CPR and its significance

\begin{tabular}{|c|c|c|c|c|c|c|c|}
\hline \multirow[t]{2}{*}{ Parameters } & \multirow{2}{*}{$\begin{array}{l}\text { No. of } \\
\text { CPF } \\
\text { children }\end{array}$} & \multicolumn{2}{|c|}{$\begin{array}{l}\text { No. of CPF patients } \\
\text { survived }\end{array}$} & \multicolumn{2}{|c|}{$\begin{array}{l}\text { No. of deaths due to } \\
\text { CPF }\end{array}$} & \multirow[t]{2}{*}{$\mathrm{p}$ value } & \multirow[t]{2}{*}{ Significance } \\
\hline & & No. & $\%$ & No. & $\%$ & & \\
\hline \multicolumn{8}{|l|}{ Blood pressure } \\
\hline BP not recordable & 14 & 5 & 35.7 & 9 & 64.2 & \multirow{2}{*}{0.3401} & \multirow{2}{*}{ NSS } \\
\hline BP recordable & 9 & 1 & 11.1 & 8 & 88.8 & & \\
\hline \multicolumn{8}{|l|}{ Respiratory rate } \\
\hline Tachypnoea & 4 & 1 & 25 & 3 & 75 & \multirow{2}{*}{1.000} & \multirow{2}{*}{ NSS } \\
\hline Bradypnoea & 19 & 4 & 21 & 15 & 78.9 & & \\
\hline \multicolumn{8}{|l|}{ Initial event of CPF } \\
\hline $\begin{array}{l}\text { Primary } \\
\text { failure }\end{array}$ & 12 & 3 & 25 & 9 & 75 & \multirow[t]{2}{*}{1.000} & \multirow[t]{2}{*}{ NSS } \\
\hline Primary Shock & 11 & 2 & 18.1 & 9 & 81.8 & & \\
\hline
\end{tabular}

NSS : Not Statistically Significant

\section{Discussion}

In the present study total number of admissions during this period into the Department of pediatrics, Govt. General Hospital, Ananthapuramu were 6024. Total number of cardiopulmonary failure and cardiopulmonary arrest were $23(0.42 \%)$ and $64(1.17 \%)$ respectively. Berg MD et al [9] have reported $2.6 \%$ of admission with cardiopulmonary arrest.

$65.1 \%$ of cases observed in $<3$ years age, rest of cases in above 3 years of age. Maximum number of cases seen in $<1$ year constituting $43.4 \%$ with slight female preponderance $(56.52 \%$ Vs $43.4 \%)$.

Majority of cases $(95.6 \%)$ with paleness rather than cyanosis $(4.3 \%)$. BP was not recordable in $60.8 \%$ of CPF cases in this study, this way reflect the time lag occur in between the onset of illness and arrival to hospital making prognosis worst.

Though all children presented with respiratory failure, $17.3 \%$ still with tachypnea for given age, this suggests the need to look for signs of respiratory failure even child is tachypnea literature search does not yield any comparative study. $86.9 \%$ of children who presented with CPF are febrile, $13 \%$ had no fever, suggestive of infectious causes of illness producing CPF as per this study. 
Children culminating into CPR an either progressing from respiratory failure (52.1\%) (or) progressively worsening from shock (47.8\%), and no direct cardiac event recorded. Reis AG et al [10] has found respiratory failure as initiating event progressing to CPA in $61 \%$ cases where as $29 \%$ were with progressively worsening shock. Department of anesthesia and accident and emergency medicine, royal liver pool children's hospital [11], Liverpool has published in 1993, as per the audit report 47\% arrests were primarily respiratory and $24 \%$ primarily cardiac in origin.

In this study Mortality rate was observed in 18 (43.4\%) CPF patients out of 23, even after Cardiopulmonary Resuscitation. Among $87 \mathrm{CPF}$ and CPA patients, survival rate was observed in 18 patients $(20.6 \%)$. Survival rate is nil in CPA patients. Majority of deaths were observed in <3 years of age group (12 out of 20 CPF deaths)

One research study from Kenya with title of "Characteristics and outcome of Cardiopulmonary resuscitation in hospitalized African children" [12] documented that 25/82 (30\%) patients with respiratory arrest survive initial cardiopulmonary resuscitation compared to 5/32 (16\%) with cardiopulmonary arrest. Survival at discharge was $22 \%(18 / 82)$ in children who had respiratory arrest while no one with cardiopulmonary arrest survive at discharge. A Retrospective study from Tamil Nadu [13] reported that survival after a cardiopulmonary arrest in the hospital was $18.4 \%$ and $14.4 \%$ were above alive at discharge.

\section{Conclusion}

In our study CPF cases were mostly seen in children of $<3$ years age group. Majority of children presented with bradypnea and paleness and common initial event of CPF were primary respiratory failure and primary shock.

In India the first PALS courses were initiated under the auspices the Indian Academy of Pediatrics (IAP) in 1994, and are now a successful training course. The overall effect of these courses on patient outcome in India is unknown; however, anecdotally, more arrests/ failure are being successfully resuscitated and mortality is lower.

In view of these facts, studies are needed in India to know the effectiveness of PALS courses in reviving the case of $\mathrm{CPA} / \mathrm{CPF}$ and also to find out the lacunae in implementing PALS courses, so that they can be rectified and more number of children is given new life.

\section{Acknowledgements}

We would like to thank staff of emergency services for helping us while doing this study.

\section{References}

[1]. J.N. Jameson St C, Dennis L Kasper, Harrison Tinsley Randolph, Braunwald Eugene, Fauci Anthony S Hauser, Stephen L Longo, Dan L, Harrison's principles of internal medicine, (New York: McGraw-Hill Medical Publishing Division 2005).

[2]. P. Safar, F. Xiao, A. Radovsky et al, Improved cerebral resuscitation from cardiac arrest in dogs with mild hypothermia plus blood flow promotion, Stroke, 27 (1), 1996 Jan, 105-13.

[3]. M. Rippe James M, S. Irwin Richard S, Irwin and Rippe's intensive care medicine, Hagerstwon MD, (Lippincott Williams \& Wilkins, 2003)

[4]. Erika E Tress, Patrick M Kochanek, Richard A Saladino, and Mioara D Manole J, Cardiac arrest in children Emerg Trauma Shock,3(3), 2010 Jul-Sep, 267-272.

[5]. D.L. Atkins, S. Everson-Stewart, G.K. Sears, M. Daya, M.H. Osmond, C.R Warden et al, Epidemiology and outcomes from out-ofhospital cardiac arrest in children: The resuscitation outcomes consortium epistry-cardiac arrest. Circulation, 119, 2009, 1484-91.

[6]. P.E. Sirbaugh, P.E. Pepe, J.E. Shook, K.T. Kimball, M.J. Goldman, M.A. Ward et al, A prospective, population-based study of the demographics, epidemiology, management, and outcome of out-of-hospital pediatric cardiopulmonary arrest, Ann Emerg Med, 33,1999,174-84.

[7]. M. Kuisma, P. Suominen P, Korpela R, Paediatric out-of-hospital cardiac arrests-epidemiology and outcome.Resuscitation, 30, $1995,141-50$.

[8]. PALS guidelines, Pediatric advanced life support, provider manual 2010.

[9]. A.A. Topjian, V.M. Nadkarni, R.A. Berg, Cardiopulmonary resuscitation in children, Curr Opin Crit Care, 15(3), 2009 Jun, $203-8$.

[10]. A.G. Reis, V. Nadkarni, M.B.Perondi, S.Grisi, R.A. Berg, A prospective investigation into the epidemiology of in-hospital pediatric cardiopulmonary resuscitation using the international Utstein reporting style, Pediatrics, 109(2), 2002 Feb, 200-9.

[11]. P.A Innus, C.A Summers, I.M Boyd, E.M Molyneux, Audit of Pediatric cardiopulmonary failure, Archives of diseases in children, 68, 1993, 487-491.

[12]. A.Olotu, M. Ndiritu, M. Ismael, S. Mohammed, S. Mithwani, K. Maitland, C.R. Newton, Characteristics and outcome of cardiopulmonary resuscitation in hospitalized African children. Resuscitation, 80(1), 2009 Jan, 69-72.

[13]. R. Rajaram, R.E. Rajagopalan, M Pal, S, Mahendran. Survival after cardiopulmonary resuscitation in an Urban Indian Hospital, In Natl Med J India, 12(2),1999 Mar-April, 51-55. 